\title{
CORRIGENDUM
}

\section{Tryptophan hydroxylase 2 (TPH2) gene variants associated with ADHD}

K Sheehan, N Lowe, A Kirley, C Mullins, M Fitzgerald, M Gill and Z Hawi

Department of Genetics and Psychiatry, Trinity College Dublin, Ireland

Molecular Psychiatry (2006) 11, 221. doi:10.1038/sj.mp.4001771

Correction to: Molecular Psychiatry (2005) 10, 944-949. doi:10.1038/sj.mp.4001698

Following publication of the above article, the authors identified the following error: the reverse
PCR primers (Table 1) and the extension primer sequence for marker rs1843809 in Table 1 on page 946 have been incorrectly labeled as $3^{\prime}-5^{\prime}$ when they in fact are $5^{\prime}-3^{\prime}$. 